\title{
Can intraoperative hyperlactatemia have an impact on early postoperative infections in patients undergoing laparoscopic colorectal cancer surgery?
}

\author{
Selçuk Gülmez, ${ }^{1}$ Orhan Uzun, ${ }^{1}$ Aziz Serkan Senger, ${ }^{1}$ Zehra Zeynep Keklikkıran, ${ }^{1}$ \\ Sinan Ömeroğlu, ${ }^{1}$ - Hilmi Bozkurt, ${ }^{2}$ Deniz Avan, ${ }^{3} \odot$ Uğur Duman,, ${ }^{4}$ Erdal Polat, ${ }^{1}$ \\ Mustafa Duman ${ }^{1}$
}

'Department of Gastrointestinal Surgery, University of Health Sciences, Kartal Kosuyolu Higher Specialty Training and Research Hospital, Istanbul, Turkey

${ }^{2}$ Department of General Surgery, University of Health Sciences, Haseki Training and Research Hospital, Istanbul, Turkey

${ }^{3}$ Department of Anesthesia, University of Health Sciences, Kartal Kosuyolu Higher Specialty Training and Research Hospital, Istanbul, Turkey

${ }^{4}$ Department of General Surgery, University of Health Sciences, Bursa Higher Specialty Training and Research Hospital, Bursa, Turkey

\begin{abstract}
Introduction: The impact of major surgery on tissue hypoxia can be evaluated indirectly with lactate at the end of the operation. This study aimed to investigate the impact of hyperlactatemia on early postoperative infectious complications at the end of surgery.

Materials and Methods: We retrospectively examined 75 patients who underwent laparoscopic resection for colorectal cancer (CRC). Lactate levels above $2 \mathrm{~mm} / \mathrm{L}$ was defined as hyperlactatemia at the end of the surgery. Postoperative infectious complications occurred within the first 30 days were included in the study. The patients were divided into two groups as those with and without postoperative infection (POI).

Results: Nineteen patients $(25.3 \%)$ had early POI complications. Patients in the POI group had a significant association with the Charlson Comorbidity Index $(\mathrm{CCl}) \geq 3(\mathrm{p}=0.021)$ and type 2 diabetes mellitus (DM) $(p=0.003)$. Hyperlactatemia was found to significsantly affect $P O I(p=0.013)$. Lactate levels increased in 16 (84.2\%) of 19 POI patients. While the median value for the hospital stay was 7 days for those without POI, it was 11 days for those with $\mathrm{POI}(\mathrm{p}=0.002)$. There was a significant relationship between general surgery site infection I (SSI) and diabetes mellitus ( $p=0.006)$, and length of hospital stay $(p=0.001)$.

Conclusion: In this study, $\mathrm{CCl} \geq 3$, type $2 \mathrm{DM}$, and hyperlactatemia at the end of the operation were independent risk factors for POI in laparoscopic colorectal cancer surgery patients. SSI and POI may predict the prolonged hospital stay. To validate these findings, studies with a higher patient volume in a prospective design are required.
\end{abstract}

Keywords: Colorectal cancer; hyperlactatemia; infections; lactate. 


\section{Introduction}

Despite all prevention efforts, colorectal cancer (CRC) continues to retain its potential to stay ahead in prevalence. CRC is the third most commonly diagnosed cancer worldwide and the second in terms of cancer-related deaths. ${ }^{[1]}$

Surgical treatment remains the primary treatment option. Patients who have undergone colorectal surgery for any reason can develop postoperative complications in up to $1 / 3$ of the patients. The overall surgical site infection (SSI) is $9.4 \%$. The rate of anastomotic leakage is between $3 \%$ and $10 \%{ }^{[2,3]}$ Pulmonary infection rate after colectomy is $6.2 \% \cdot{ }^{[4]}$ After the use of laparoscopy became widespread, CRC closely followed these technological developments. Nowadays, due to its many advantages, such as short hospitalization, better cosmetics, less incisional hernia, etc. the laparoscopic approach is preferred by many clinics without neglecting oncological results. ${ }^{[5]}$ It was reported that laparoscopic colorectal surgery reduced SSI in a meta-analysis involving 5797 patients, including sixteen randomized controlled trials. ${ }^{[6]}$ Besides, the positive effects of laparoscopy on hospital stay were accepted by everyone.

Prolonged operative time, such as cancer surgery, may increase lactate levels secondary to tissue hypoperfusion. An increased intraabdominal pressure (IAP) in laparoscopy reduces splanchnic blood flow and impairs tissue perfusion. ${ }^{[7]}$ In addition, an IAP increase also reduces hepatic and renal blood flow, which are the elimination organs of lactate. ${ }^{[8]}$ As a result of all these effects, laparoscopic surgery may be associated with increased lactate levels.

The decrease in oxygen support and tissue hypoxia due to microvascular flow impairment underlies the complications after major surgery. Lactate is an essential marker of hypoperfusion. ${ }^{[9]}$ The effect of major surgery on tissue hypoxia can be indirectly evaluated with lactate at the end of the operation. ${ }^{[10]}$

Many studies in the literature highlight the prognostic importance of hyperlactatemia. ${ }^{[11]}$ We hypothesize that intraoperative hyperlactatemia may affect early postoperative infective outcomes.

Our aim in this study was to investigate the effect of hyperlactatemia at the end of surgery on early postoperative infectious complications.

\section{Materials and Methods}

Ethical approval (Ethical Committee No. 2019.4/23-200) was provided by the Institutional Research and Ethics Committee of our hospital. This committee waived the need for informed consent from all eligible patients.

We retrospectively enrolled 75 patients who underwent laparoscopic resection for colorectal cancer in our center between January 2013 and June 2019. In this study, exclusion criteria were emergency surgery or palliative surgery, under 18 years of age, and conversion to open surgery. Initial lactate levels were determined from blood gas analysis before the incision. The end lactate values were recorded at the completion of the operation. Patients, those who had an initial intra-arterial blood lactate level higher than $2 \mathrm{mmol} / \mathrm{L}$, were excluded from the analysis. Patients with chronic kidney, liver, and heart disease with impaired organ function were also excluded from the study. Hyperlactatemia defined as lactate levels exceed $2 \mathrm{~mm} / \mathrm{L}$ at the end of the surgery. ${ }^{[12]}$ Postoperative infectious complications within the first 30 days were included in this study. These were pulmonary, urinary tract, and central-venous-catheter-related bloodstream infections. Incisional SSI (superficial and deep) and organ-space SSI, such as anastomotic leak and intraabdominal abscess, were also recorded. The patients were divided into two groups as those with and without postoperative infection (POI).

Standard anesthesia induction was applied to all patients with 1-2 mcg/ $\mathrm{kg}$ fentanyl, $2 \mathrm{mg} / \mathrm{kg}$ propofol, and $0.1 \mathrm{mg} /$ $\mathrm{kg}$ rocuronium. Maintenance of the sevoflurane dose was adjusted with the Bispectral Index (BIS) monitoring in the range of $0.8-1$ minimum alveolar concentration (MAC). We performed rectal cancer surgery partially in the Trendelenburg position. The pneumoperitoneum pressure of the patients was adjusted as $12-14 \mathrm{mmHg}$.

The demographic, clinical, and surgical characteristics of the patients were included in the study. The variables were age, sex, Charlson comorbidity index (CCI), ${ }^{[13]}$ American Society of Anesthesiologists (ASA) score, BMI, type 2 diabetes mellitus (DM), hyperlactatemia, tumor localization, tumor size, TNM stage, and length of hospital stay. Operative details included total volume of administered fluids, the volume of urine output, the volume of blood loss, and surgery time.

\section{Statistical Analysis}

The SPSS (Statistical Product and Service Solutions) software version 22 for Windows (SPSS Inc. Chicago, IL, USA) was used for statistical analyses of the study. The 
normality of the distribution of the data was carried out using the Kolmogorov-Smirnov test. Qualitative data were presented as frequency and percentage. Quantitative data were given as mean $\pm S D$ if the data were normally distributed, and median (Interquartile Range-IQR) if not normally distributed. The association of postoperative infective complications with categorical variables was analyzed using Chi-square and Fisher's exact tests. The Mann-Whitney-U test was used to examine whether postoperative infections were related to blood loss, administered fluid volume, urine output, and length of hospital stay. The effect of operative time on postoperative infective complications was investigated with the student's t-test. A p-value lower than 0.05 was accepted as statistically significant.

\section{Results}

Of the 75 patients, 19 (25.3\%) had early postoperative infective complications. Table 1 shows the demographic, clinical, and surgical characteristics of patients. The median age of the POI group was 62 (56-72), while the other group without infection was 60 (50-66). Seven out of 24 elderly patients struggle with an infection after the operation $(p=0.601)$. In the infective group, the femalemale ratio was very close to each other $(p=0.943)$. It was observed that patients in the infective group had a significant association with $\mathrm{CCI} \geq 3$ ( $\mathrm{p}=0.021)$. Eight $(42.1 \%)$ of these 19 patients with POI had Type $2 \mathrm{DM}$, and this was a facilitating factor for POI $(\mathrm{p}=0.003)$. Another parameter in this study that had a significant relationship with POI and affected it was hyperlactatemia ( $\mathrm{p}=0.013)$. Lactate levels were elevated in 16 (84.2\%) of 19 POI patients. Those without POI stayed in the hospital for 7 days as the median value, while those with POI stayed for 11 days $(\mathrm{p}=0.002)$. There was no significant association between the other variables included in the study and POI.

Table 2 shows the types of postoperative infections in patients with hyperlactatemia. The most common of these complications was incisional SSI, and it affected 5 of the 16 patients. The incidence of incisional SSI in all patients was $6.6 \%$. Three patients with anastomotic leak followed this complication. One patient had to undergo a percutaneous procedure due to intraabdominal abscess. The incidence of organ/space SSI was 8.0\%, and the overall SSI was $12.0 \%$. Pulmonary infections were also observed in three patients. Urinary tract infection and central-venous- catheter-related bloodstream infections were detected in two patients in both.

Table 3 shows the significant relationship between overall SSI and diabetes mellitus $(\mathrm{p}=0.006)$ and length of hospital stay $(\mathrm{p}=0.001)$.

\section{Discussion}

In this study, we aimed to investigate the effect of intraoperative hyperlactatemia on early postoperative infective complications based on a retrospective analysis of a total of 75 patients who had laparoscopic surgery due to colorectal cancer. Our results showed that increased Charlson comorbidity index ( $\mathrm{CCI} \geq 3$ ), type II DM, and hyperlactatemia were a significant risk factor for infections in the early postoperative period. It was also found that patients with POI had prolonged hospital stays.

So far, many studies have been conducted with risk factors for CRC complications. It is possible to collect all of these in the subgroup related to the patient, the disease, and the operation. Examples include advanced age, male gender, high ASA score and CCI, prolonged operation time, high blood loss, advanced cancer stage. ${ }^{[2]}$ It is possible to increase the numbers of these variables. Many of the parameters that facilitate this infection are associated with impaired oxygen delivery to the tissue. Hypoxic conditions cause a series of chains of events in which lactate plays a vital role. Bakker et al. ${ }^{[14]}$ reported that high CCI is a risk factor for an anastomotic leak. In those with comorbidity, pulmonary (6.2\%) and urinary tract infection (5\%) were the most frequent complications. ${ }^{[15]}$ Similar results for overall infectious complications in high CCI status were also valid in our study.

Laparoscopic surgery is a minimally invasive procedure, and it is associated with less SSI compared to conventional surgery. The incidence of incisional SSI ranges from 3.3\% ${ }^{[16]}$ to $26 \%{ }^{[17]}$ Poon et al. ${ }^{[18]}$ reported the organ/space SSI incidence rate as $2.7 \%$. The overall incisional and organ/space SSI rate in our study was $12.0 \%, 6.6 \%$, and $5.3 \%$, respectively. It was compatible with the literature. Operative factors for the SSI are more critical than patient factors. ${ }^{[16]}$

Diabetes is a generally accepted risk factor for infectious complications after surgery. ${ }^{[19]} \mathrm{DM}$ was also found to be closely related to SSI. ${ }^{[20]}$ In our study, type $2 \mathrm{DM}$, similar to most literature results, was in a significant association with both overall infection and SSI. 
Table 1. Demographic, clinical, and surgical characteristics of the patients

Total patients $(n=75)$

\begin{tabular}{|c|c|c|c|c|c|}
\hline \multirow[b]{4}{*}{ Variables } & \\
\hline & \multicolumn{4}{|c|}{ Postoperative infection (POI) } & \multirow[b]{3}{*}{$\mathbf{p}$} \\
\hline & \multicolumn{2}{|c|}{ No $(n=56)(74.7 \%)$} & \multicolumn{2}{|c|}{ Yes $(n=19)(25.3 \%)$} & \\
\hline & $\mathbf{n}$ & $\%$ & $\mathbf{n}$ & $\%$ & \\
\hline \multicolumn{6}{|l|}{${ }^{a}$ Age, 65 years } \\
\hline$<65$ & 39 & 69.6 & 12 & 63.2 & 0.601 \\
\hline$\geq 65$ & 17 & 30.4 & 7 & 36.8 & \\
\hline \multicolumn{6}{|l|}{ asex } \\
\hline Male & 30 & 53.6 & 10 & 52.6 & 0.943 \\
\hline Female & 26 & 46.4 & 9 & 47.4 & \\
\hline \multicolumn{6}{|l|}{${ }^{\mathrm{a} B M I} \mathrm{~kg} / \mathrm{m}^{2}$} \\
\hline$<30$ & 39 & 69.6 & 10 & 52.6 & 0.178 \\
\hline$\geq 30$ & 17 & 30.4 & 9 & 47.4 & \\
\hline \multicolumn{6}{|l|}{${ }^{\mathrm{a}} \mathrm{CCl}$} \\
\hline$<3$ & 40 & 71.4 & 8 & 42.1 & 0.021 \\
\hline$\geq 3$ & 16 & 28.6 & 11 & 57.9 & \\
\hline \multicolumn{6}{|l|}{${ }^{a}$ ASA score } \\
\hline$I-I \mid$ & 26 & 46.4 & 5 & 26.3 & 0.124 \\
\hline III-IV & 30 & 53.6 & 14 & 73.7 & \\
\hline \multicolumn{6}{|l|}{ 'bType 2 DM } \\
\hline No & 51 & 91.1 & 11 & 57.9 & 0.003 \\
\hline Yes & 5 & 8.9 & 8 & 42.1 & \\
\hline \multicolumn{6}{|l|}{ 'bocalization } \\
\hline Colon & 41 & 73.2 & 15 & 78.9 & 0.765 \\
\hline Rectum & 15 & 26.8 & 4 & 21.1 & \\
\hline \multicolumn{6}{|l|}{ aTumor size } \\
\hline$<5 \mathrm{~cm}$ & 45 & 80.4 & 15 & 78.9 & $>0.999$ \\
\hline$\geq 5 \mathrm{~cm}$ & 11 & 19.6 & 4 & 21.1 & \\
\hline \multicolumn{6}{|l|}{ aHyperlactatemia } \\
\hline No & 27 & 48.2 & 3 & 15.8 & 0.013 \\
\hline Yes & 29 & 51.8 & 16 & 84.2 & \\
\hline \multicolumn{6}{|l|}{ aTNM stage } \\
\hline$I-I I$ & 35 & 62.5 & 13 & $68.4 \%$ & 0.621 \\
\hline \multirow[t]{2}{*}{ III-IV } & 21 & 37.5 & 6 & $31.6 \%$ & \\
\hline & \multicolumn{5}{|c|}{ Mean $\pm S D$ or Median (IQR) } \\
\hline${ }^{c}$ Operative time/min & & $208 \pm 55$ & & $216 \pm 68$ & 0.605 \\
\hline${ }^{\mathrm{d} B l o o d}$ loss $/ \mathrm{mL}$ & & $50(40-100)$ & & $75(50-150)$ & 0.162 \\
\hline${ }^{\mathrm{d} A d m i n i s t e r e d ~ C r y s t a l l o i d ~} / \mathrm{mL}$ & & $2000(1500-2900)$ & & $2000(1500-3000)$ & 0.932 \\
\hline dUrine output/mL-h & & $50(45-65)$ & & $55(50-70)$ & 0.224 \\
\hline dLength of hospital stay/day & & $7(6-8)$ & & $11(7-14)$ & 0.002 \\
\hline
\end{tabular}

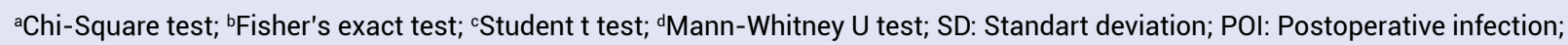
BMI: Body mass index; CCl: Charlson comorbidity index; ASA: American society of anesthesiologists; DM: Diabetes mellitus. 
Table 2. Types of postoperative infections in patients with hyperlactatemia

\section{POI and Hyperlactatemia}

\begin{tabular}{lc}
\hline Type of the POI & $\mathbf{n = 1 6}$ \\
\hline Incisional SSI & 5 \\
Anastomotic leak & 3 \\
Pulmonary infection & 3 \\
Urinary tract infection & 2 \\
Central-venous-catheter-related & 2 \\
bloodstream infection & \\
Intra-abdominal abscess & 1 \\
\hline POI: Postoperative infection; SSI: Surgical site infection & \\
\hline
\end{tabular}

Hyperlactatemia, defined by blood lactate level $>2$, is an important key to sepsis and shock. ${ }^{[21]}$ Lactate can predict complications as an indirect tissue hypoxia marker. ${ }^{[9]}$ Any major surgical procedure triggers a series of reaction chains by stimulating neuroendocrine and inflammatory responses and then leads to an increase in tissue oxygen consumption. Adequate oxygen delivery is essential in anastomosis in colorectal surgery. Challenge and extended interventions such as cancer surgery and increased IAP in laparoscopy can increase lactate values and decrease intestinal blood flow by causing hypoperfusion in the splanchnic area. These conditions can also endanger anastomosis. ${ }^{[22-24]}$ Also, increased IAP with pneumoperitoneum leads to reduced blood flow of the liver and kidneys, which prevents lactate from being excreted from the body. ${ }^{[7]}$ Thus, hyperlactatemia can be seen in laparoscopic colorectal cancer surgery.

Colorectal surgery has four times increased SSI compared to other abdominal procedures. ${ }^{[19]}$ In the review of An et al., ${ }^{[25]}$ patients with colorectal resection by laparoscopic approach had increased hospitalization times compared to those without SSI.

Yates et al. ${ }^{[22]}$ reported that elevated lactate values at postoperative 3rd hour independently predicted major complications and prolonged length of hospital stay. According to the results of this present study, those with POI and SSI were related to extended stays in the hospital.

This study had some limitations. The retrospective model and the relatively small patient volume were the leading ones.

\section{Conclusions}

In this study, conducted in patients with laparoscopic colorectal cancer surgery, CCI $\geq 3$, type $2 \mathrm{DM}$, and hyperlactatemia at the end of the operation were independent risk factors for POI. POI and SSI may predict the prolonged length of hospital stay. To confirm these outcomes, high volume studies in the prospective design are required.

\section{Disclosures}

Ethichs Committee Approval: Ethical approval (Ethical Committee No. 2019.4/23-200) was provided by the Institutional Research and Ethics Committee of our hospital. This committee waived the need for informed consent from all eligible patients.

Peer-review: Externally peer-reviewed.

Conflict of Interest: None declared.

Table 3. Relationship between overall SSI and diabetes mellitus and length of hospital stay

\begin{tabular}{|c|c|c|c|c|c|}
\hline & \multicolumn{4}{|c|}{ Overall SSI (n=9) } & \multirow{3}{*}{ p } \\
\hline & \multicolumn{2}{|c|}{ No } & \multicolumn{2}{|c|}{ Yes } & \\
\hline & $n$ & $\%$ & $\mathbf{n}$ & $\%$ & \\
\hline \multicolumn{6}{|l|}{ aDiabetes mellitus } \\
\hline No & 58 & 87.9 & 4 & 44.4 & 0.006 \\
\hline Yes & 8 & 12.1 & 5 & 55.6 & \\
\hline bLength of hospital stay/day & \multicolumn{2}{|c|}{66} & \multicolumn{2}{|c|}{9} & 0.001 \\
\hline
\end{tabular}


Authorship Contributions: Concept - S.G.; Design S.G.; Supervision - O.U., A.S.S.; Materials - H.B.; Data collection and/or processing - Z.K.K., H.B.; Analysis and/ or interpretation - U.D., S.G., D.A.; Literature search - S.G., S.Ö.; Writing - S.G.; Critical review - E.P., M.D.

\section{References}

1. Bray F, Ferlay J, Soerjomataram I, Siegel RL, Torre LA, Jemal A. Global cancer statistics 2018: GLOBOCAN estimates of incidence and mortality worldwide for 36 cancers in 185 countries. CA Cancer J Clin 2018;68:394-424. [CrossRef]

2. Tevis SE, Kennedy GD. Postoperative Complications: Looking Forward to a Safer Future. Clin Colon Rectal Surg 2016;29:246-52. [CrossRef]

3. Huh JW, Lee WY, Park YA, Cho YB, Kim HC, Yun SH, et al. Oncological outcome of surgical site infection after colorectal cancer surgery. Int J Colorectal Dis 2019;34:277-83. [CrossRef]

4. Longo WE, Virgo KS, Johnson FE, Oprian CA, Vernava AM, Wade TP, et al. Risk factors for morbidity and mortality after colectomy for colon cancer. Dis Colon Rectum 2000;43:83-91.

5. Brisinda G, Vanella S, Giustacchini P, Cavicchioni C, Crocco A, Maria G. Open versus laparoscopic colorectal surgery in the era of multimodality treatment of cancer. Ann Ital Chir 2013;84:563-70.

6. Kulkarni N, Arulampalam T. Laparoscopic surgery reduces the incidence of surgical site infections compared to the open approach for colorectal procedures: a meta-analysis. Tech Coloproctol 2020;24:1017-24. [CrossRef]

7. Tolan HK, Ezberci F. Abdominal effects of laparoscopic surgery. Laparosc Endosc Surg Sci 2017;24:67-73. [CrossRef]

8. Hashikura Y, Kawasaki S, Munakata Y, Hashimoto S, Hayashi $\mathrm{K}$, Makuuchi M. Effects of peritoneal insufflation on hepatic and renal blood flow. Surg Endosc 1994;8:759-61. [CrossRef]

9. Jhanji S, Lee C, Watson D, Hinds C, Pearse RM. Microvascular flow and tissue oxygenation after major abdominal surgery: association with post-operative complications. Intensive Care Med 2009;35:671-7. [CrossRef]

10. Peng K, Li J, Cheng H, Ji FH. Goal-directed fluid therapy based on stroke volume variations improves fluid management and gastrointestinal perfusion in patients undergoing major orthopedic surgery. Med Princ Pract 2014;23:413-20.

11. Rishu AH, Khan R, Al-Dorzi HM, Tamim HM, Al-Qahtani S, Al-Ghamdi G, et al. Even mild hyperlactatemia is associated with increased mortality in critically ill patients. Crit Care 2013;17:R197. [CrossRef]
12. Gómez H, Mizock BA. Hyperlactatemia and Lactic Acidosis. In: Ronco C, Bellomo R, Kellum JA, Ricci Z, editors. Critical care nephrology. 3rd ed. Philadelphia: Elsevier; 2019. p. 394-404.

13. Charlson ME, Pompei P, Ales KL, MacKenzie CR. A new method of classifying prognostic comorbidity in longitudinal studies: development and validation. J Chronic Dis 1987;40:373-83.

14. Bakker IS, Grossmann I, Henneman D, Havenga K, Wiggers T. Risk factors for anastomotic leakage and leak-related mortality after colonic cancer surgery in a nationwide audit. $\mathrm{Br} \mathrm{J}$ Surg 2014;101:424-32; discussion 432. [CrossRef]

15. Kirchhoff P, Clavien PA, Hahnloser D. Complications in colorectal surgery: risk factors and preventive strategies. Patient Saf Surg 2010;4:5. [CrossRef]

16. Chida K, Watanabe J, Suwa $Y$, Suwa H, Momiyama M, Ishibe $A$, et al. Risk factors for incisional surgical site infection after elective laparoscopic colorectal surgery. Ann Gastroenterol Surg 2019;3:202-8. [CrossRef]

17. Smith RL, Bohl JK, McElearney ST, Friel CM, Barclay MM, Sawyer RG, et al. Wound infection after elective colorectal resection. Ann Surg 2004;239:599-605; discussion 605-7.

18. Poon JT, Law WL, Wong IW, Ching PT, Wong LM, Fan JK, et al. Impact of laparoscopic colorectal resection on surgical site infection. Ann Surg 2009;249:77-81. [CrossRef]

19. Pak H, Maghsoudi LH, Soltanian A, Gholami F. Surgical complications in colorectal cancer patients. Ann Med Surg (Lond) 2020;55:13-8. [CrossRef]

20. Martin ET, Kaye KS, Knott C, Nguyen H, Santarossa M, Evans $\mathrm{R}$, et al. Diabetes and Risk of Surgical Site Infection: A Systematic Review and Meta-analysis. Infect Control Hosp Epidemiol 2016;37:88-99. [CrossRef]

21. Bangash MF. Sepsis: an update in 2018. Anaesth Pain \& Intensive Care 2018;22:99-101. [CrossRef]

22. Yates DRA, Davies SJ, Warnakulasuriya SR, Wilson RJT. Volume Management and Resuscitation in Colorectal Surgery. Curr Anesthesiol Rep 2014;4:376-85. [CrossRef]

23. Liu L, Lv N, Hou C. Effects of a multifaceted individualized pneumoperitoneum strategy in elderly patients undergoing laparoscopic colorectal surgery: A retrospective study. Medicine (Baltimore) 2019;98:e15112. [CrossRef]

24. Gutt CN, Oniu T, Mehrabi A, Schemmer P, Kashfi A, Kraus T, et al. Circulatory and respiratory complications of carbon dioxide insufflation. Dig Surg 2004;21:95-105. [CrossRef]

25. An SH, Youn MK, Kim IY. Effect of laparoscopic surgery on the risk for surgical site infections in colorectal resection: results from the Health Insurance Review \& Assessment Service Database. Ann Surg Treat Res 2020;98:315-23. [CrossRef] 